\title{
Medidas repetidas no tempo realizadas por ultrassom em ovelhas de descarte em diferentes estágios fisiológicos
}

\section{Measurements repeated in time carried out by ultrasound in discard ewes in different physiological stages}

\author{
Rafael Silvio Bonilha Pinheiro ${ }^{1 *}$; André Mendes Jorge ${ }^{2}$; \\ Cristiano Magalhães Pariz ${ }^{3}$; Marcos Jun Iti Yokoo ${ }^{4}$
}

\begin{abstract}
Resumo
Monitoraram-se algumas medidas realizadas no Longissimus dorsi entre a $12^{\mathrm{a}}$ e $13^{\mathrm{a}}$ costelas por ultrassom, com objetivo de conhecer as mudanças que ocorrem com os tecidos muscular e adiposo neste músculo e a relação destas medidas com o peso corporal (PC) e com o escore de condição corporal (ECC) de ovelhas em diferentes fases (estágios fisiológicos e períodos experimentais). As ovelhas foram distribuídas nos respectivos tratamentos: $\mathrm{OL}=$ ovelhas que permaneceram por 60 dias em lactação com seus respectivos cordeiros e abatidas um dia após o desmame dos mesmos; OSC = ovelhas que permaneceram por 60 dias em lactação com seus respectivos cordeiros e mais um período de 30 dias sem os cordeiros e posteriormente foram abatidas; ONP = ovelhas que não pariram durante o ano. As medidas por ultrassom foram realizadas no início, no meio e no fim do trabalho (períodos experimentais de 21 dias cada), assim como o PC e a ECC das ovelhas. Não houve interação entre os períodos e tratamentos experimentais para o PC e para a ECC das ovelhas. Concluiu-se que a utilização do ultrassom permite monitorar as mudanças que ocorrem com a gordura subcutânea e com o Longissimus dorsi de ovelhas. Mudanças estas que ocorrem com uma frequência maior em intervalos de 42 dias entre avaliações dos tecidos muscular e adiposo.
\end{abstract}

Palavras-chave: Área de olho de lombo, condição corporal, espessura de gordura subcutânea, ovinos, peso corporal

\begin{abstract}
Some measurements carried out by ultrasound in the Longissimus dorsi between the 12th and 13th ribs were monitored, aiming to know the changes in the muscular and adipose tissues in that muscle and the connections of these measurements with body weight (BW) and body condition score (BCS) of ewes in different stages (physiological stages and experimental periods). Ewes were arranged into the following treatments: $\mathrm{EL}=$ ewes which remained in lactation for 60 days with their respective lambs and slaughtered one day after weaning; $E W L=$ ewes which remained in lactation for 60 days with their respective lambs and one more period of approximately 30 days without the lambs and slaughtered afterwards; and $\mathrm{ENC}=$ ewes which did not give birth during the year. Ultrasound measurements were
\end{abstract}

\footnotetext{
${ }^{1}$ Prof. Dr., Universidade Estadual Paulista "Júlio de Mesquita Filho" da Faculdade de Engenharia UNESP/FEIS, Ilha Solteira, SP. E-mail: rafaelsbp@bio.feis.unesp.br

${ }^{2}$ Prof. Adjunto, Faculdade de Medicina Veterinária e Zootecnia UNESP/FMVZ, Botucatu, SP. E-mail: andrejorge@fmvz.unesp. br

${ }^{3}$ Pós-Doutorado, Faculdade de Medicina Veterinária e Zootecnia, UNESP/FMVZ, Botucatu, SP. E-mail: cmpzoo@gmail.com

${ }^{4}$ Pesquisador da Empresa Brasileira de Pesquisa Agropecuária, Centro de Pesquisa de Pecuária dos Campos Sul-Brasileiros, CPPSUL, Embrapa Pecuária Sul, Bagé, RS. E-mail: marcos.yokoo@embrapa.br

* Autor para correspondência
} 
carried out in the beginning, middle and end of the experiment (every 21 days), as well as BW and $\mathrm{BCS}$ of ewes. There was not interaction between periods and experimental treatments for BW and BCS of ewes. It was concluded that the use of ultrasound allows monitoring changes that occur with the subcutaneous fat and Longissimus dorsi of ewes. Those changes occur more frequently in intervals of 42 days (muscular and adipose tissues).

Key words: Body condition, body weight, loin eye area, sheep, subcutaneous fat thickness

\section{Introdução}

A avaliação da carcaça in vivo, possibilita conhecer o desenvolvimento muscular e adiposo do animal. Porém, na maioria dos casos esta avaliação é realizada subjetivamente por inspeção visual ou palpação da região dorsal da coluna vertebral do animal, podendo acarretar em erros no momento da sua realização (FROST et al., 1997). O equipamento de ultrassom pode ser uma alternativa para determinar in vivo as características da carcaça ovina com maior precisão.

De acordo com Thwaites (1984), a técnica de ultrassom está disponível para a avaliação de carcaças suínas, bovinas e ovinas, desde os anos 50. No entanto, a utilização do ultrassom no Brasil com tal finalidade ainda encontra-se em fase inicial, principalmente para espécie ovina.

O monitoramento das características in vivo no animal, como a área de olho de lombo (AOL), a espessura de gordura subcutânea (EGS) e demais medidas realizadas no músculo Longissimus dorsi entre a $12^{\mathrm{a}}$ e $13^{\mathrm{a}}$ costelas, possibilita acompanhar as mudanças dos tecidos constituintes da carcaça do animal, desde que, estas medidas sejam realizadas mais de uma vez, para comparação das mesmas. A mobilização das reservas corporais (tecidos adiposos e musculares) após o parto das fêmeas é fato conhecido e acarreta, normalmente, perda de peso e do índice de condição corporal do animal principalmente no início da lactação, seguida de posterior recuperação (total ou parcial) do peso corporal e da condição corporal no fim ou após a lactação (PEDRON et al., 1993; WALTNER; McNAMARA; HILLERS, 1993). Tal fato ocorre desde que os animais tenham alimentação em quantidade e de boa qualidade e estejam sadios. No entanto, não se sabe com precisão quanto de tecido adiposo e muscular é mobilizado e novamente recuperado em ovelhas em diferentes estágios fisiológicos durante um período de produção.

Segundo Stanford et al. (1995) a pequena área do músculo Longissimus dorsi e o estreito espaço entre as costelas de caprinos jovens levam ao aumento proporcional de erros nas mensurações realizadas por ultrassom. Tal fato também ocorre com ovinos jovens. No entanto, os estudos que utilizam o ultrassom para determinar características da carcaça de ovinos são ainda escassos, principalmente com animais adultos de descarte, o que impossibilita a tomada de decisão do momento ideal do abate. Segundo Castro et al. (2012) a criação de ovinos para produção de carne tem apresentado incremento em todas as regiões do Brasil, e vem se tornando uma atividade econômica importante. De acordo com Geron et al. (2012) no Brasil, nos últimos anos, ocorreu aumento significativo na demanda de carne ovina, principalmente nos grandes centros urbanos. Portanto é oportuno estudos nesta área (características da carcaça de ovinos) utilizando o ultrassom.

Objetivou-se, com este estudo, conhecer as mudanças que ocorrem com os tecidos muscular e adiposo do Longissimus dorsi entre a $12^{\mathrm{a}}$ e $13^{\mathrm{a}}$ costelas por ultrassom e a relação destas com o peso corporal e com o escore de condição corporal dos animais nas diferentes fases (estágios fisiológicos e períodos experimentais de 21 dias).

\section{Material e Métodos}

Foram selecionados para o presente estudo 21 ovelhas de descarte da raça Santa Inês (após 
um período de estação de monta) de um rebanho comercial localizado na cidade de Jaguariúna, SP Brasil. No início do estudo os animais apresentaram peso corporal médio de aproximadamente $43 \pm 2,87$ $\mathrm{kg}$, com idade média de $72 \pm 11$ meses. As fêmeas foram distribuídas nos seguintes tratamentos: $\mathrm{OL}=$ ovelhas que permaneceram por 60 dias em lactação com seus respectivos cordeiros e abatidas um dia após o desmame dos mesmos; OSC = ovelhas que permaneceram por 60 dias em lactação com seus respectivos cordeiros e mais um período aproximado de 30 dias sem os cordeiros, e posteriormente foram abatidas; e ONP = ovelhas que permaneceram por 60 dias juntas das ovelhas do OL e OSC até o abate e que não pariram durante o ano.

As ovelhas permaneceram em regime de confinamento em uma instalação coberta com área de solário, alimentação e água à vontade durante todo o período do experimento. Foram utilizadas 7 ovelhas por tratamento, e avaliadas quanto o escore de condição corporal, o peso corporal e quanto as medidas in vivo por ultrassom no Longissimus dorsi entre a $12^{\mathrm{a}}$ e $13^{\mathrm{a}}$ costelas de ovelhas em diferentes estágios fisiológicos, no início (período 1), no meio (período 2) e no fim do experimento (período 3).

No período 1 (avaliação inicial dos animais utilizado o ultrassom) as ovelhas do OL haviam parido naquela semana, enquanto as do OSC já haviam parido há um mês atrás e as do ONP não estavam prenhas. No período 2 (após 21 dias da primeira avaliação dos animais utilizado o ultrassom) as ovelhas do OL já tinham parido há um mês, as do OSC estavam desmamando os seus cordeiros e as do ONP não estavam prenhas. No período 3 (após 42 dias da primeira avaliação dos animais utilizado o ultrassom) as ovelhas do OL estavam desmamando seus cordeiros, as do OSC já estavam aproximadamente há 30 dias sem os seus cordeiros e as do ONP não estavam prenhas. Todos os partos foram simples (parição de um cordeiro por ovelha).

A dieta fornecida às ovelhas apresentou relação volumoso:concentrado de 70:30. O volumoso foi o feno de Tifton - 85 (Cynodon spp) e o concentrado constituído por $69,6 \%$ de grão de milho moído, $24,8 \%$ de farelo de algodão, $0,8 \%$ de calcário calcítico, $0,8 \%$ de fosfato bicálcico e $4 \%$ de suplemento mineral.

Os animais receberam duas refeições diárias, às 7 horas e às 16 horas, em cocho de madeira que permitiu o acesso de todos os animais ao mesmo tempo. Os cordeiros tiveram acesso a comedouro seletivo onde foi oferecido concentrado à vontade, no intuito de minimizar o desgaste promovido pelo período de lactação das ovelhas. Todos os animais tiveram acesso a sal comum fornecidos em cocho. A composição bromatológica da dieta foi de $89,13 \%$ de matéria seca, $4,97 \%$ de matéria mineral, $11,81 \%$ de proteína bruta, $2,12 \%$ de extrato etéreo, 58,46\% de fibra em detergente neutro e de $30,29 \%$ de fibra em detergente ácido.

A avaliação da condição corporal foi realizada por meio de escore corporal subjetivo, mediante a apalpação da coluna vertebral, logo após a última costela acima da região dos rins, conforme descrito por Russel, Doney e Gunn (1969), sendo: 0 = animal caquético a 5 = animal extremamente gordo.

As medidas por ultrassom foram realizadas após a tosquia da região entre a $12^{\mathrm{a}}$ e $13^{\mathrm{a}}$ costelas, do lado direito do animal. Utilizou-se óleo vegetal no dorso do animal, para o acoplamento acústico (standoff), o qual foi disposto de maneira perpendicular ao comprimento do músculo Longissimus dorsi para a tomada da imagem, cuja leitura foi a medida do comprimento e da profundidade máxima do músculo (CMM e PMM), em centímetros $(\mathrm{cm})$, além da espessura de gordura subcutânea (EGS), em milímetros $(\mathrm{mm})$. Determinou-se a área de olho de lombo em $\mathrm{cm}^{2}$ e a área de olho de lombo ajustada (AOLA) para $15 \mathrm{~kg}$ de carcaça $\left(\mathrm{cm}^{2} / 15 \mathrm{~kg}\right.$ de carcaça). O equipamento de ultrassom utilizado foi o PIEMEDICAL, modelo Aquila, equipado com sonda linear de $18 \mathrm{~cm}$ e $3,5 \mathrm{MHz}$, e guia acústica para o acoplamento ao animal. As imagens obtidas com o equipamento de ultrassom foram realizadas por um técnico experiente em determinar medidas in vivo em ovinos com tal aparelho. 
Para as análises de variância foi utilizado o procedimento do SAS (SAS, 2002). As médias dos tratamentos foram comparadas pelo teste de Tukey a 5\% de probabilidade. Os períodos experimentais (1, 2 e 3 ) foram analisados como medida repetida no tempo, pelo procedimento Mixed do software SAS (SAS, 2002). Para determinar o coeficiente de correlação entre as variáveis estudadas nesta pesquisa, foi utilizada a correlação de Pearson.

\section{Resultados e Discussão}

Não houve interação $(\mathrm{P}>0,05)$ entre os períodos de 21 dias e tratamentos experimentais para o escore de condição corporal e o peso corporal das ovelhas (Tabela 1). Ocorreu diferença $(\mathrm{P}<0,01)$ entre as médias dos tratamentos experimentais, para o peso corporal e para o escore de condição corporal das ovelhas (Tabela 1). As ovelhas do tratamento OL apresentaram menor $(\mathrm{P}<0,01)$ peso corporal e escore corporal do que as dos tratamentos OSC e ONP (Tabela 1). Tal fato é explicado pelo estágio fisiológico em que as ovelhas do tratamento OL se encontravam em relação às dos demais tratamentos avaliados, ou seja, encontravam-se em início de lactação, momento que há mobilização de tecidos adiposos e até musculares no animal. Godfrey, Gray e Collins (1997) também observaram perda de peso em ovelhas em lactação, sendo que as maiores perdas ocorreram no primeiro mês de lactação das mesmas, estando condizentes com o resultado deste estudo para as ovelhas do OL (Tabela 1).

Tabela 1. Determinação do escore de condição corporal e do peso corporal de ovelhas em distintos estágios fisiológicos e períodos experimentais de 21 dias cada.

\begin{tabular}{|c|c|c|c|c|}
\hline \multirow{2}{*}{ Variável } & \multicolumn{3}{|c|}{ Tratamento } & \multirow{2}{*}{ Média } \\
\hline & OL & OSC & ONP & \\
\hline \multicolumn{5}{|c|}{ Escore de condição corporal (ECC) ${ }^{1}$} \\
\hline P1 ( $1^{\circ}$ avaliação) & 1,45 & 1,75 & 2,93 & $2,04 \mathrm{~B}$ \\
\hline P2 ( $2^{\circ}$ avaliação $)$ & 1,62 & 1,82 & 3,43 & $2,29 \mathrm{~B}$ \\
\hline P3 ( $3^{\circ}$ avaliação) & 2,14 & 2,87 & 3,75 & $2,92 \mathrm{~A}$ \\
\hline Média & $1,73 \mathrm{c}$ & $2,15 b$ & $3,37 \mathrm{a}$ & \\
\hline \multicolumn{5}{|l|}{$\mathrm{CV}(\%)=18,14$} \\
\hline \multicolumn{5}{|l|}{ Teste $\mathrm{F}(\mathrm{T})=3,43 * *$. } \\
\hline \multicolumn{5}{|l|}{ Teste $\mathrm{F}(\mathrm{P})=23,38^{* *}$} \\
\hline \multicolumn{5}{|l|}{ Teste $\mathrm{F}(\mathrm{P} X \mathrm{~T})=1,57^{\mathrm{NS}}$} \\
\hline \multicolumn{5}{|l|}{ Peso corporal $(\mathrm{PC})^{2}$} \\
\hline P1 $\left(1^{\circ}\right.$ pesagem $)$ & 41,57 & 44,30 & 44,81 & $43,56 \mathrm{~A}$ \\
\hline P2 $\left(2^{\circ}\right.$ pesagem $)$ & 40,58 & 43,68 & 45,74 & $43,33 \mathrm{~A}$ \\
\hline P3 $\left(3^{\circ}\right.$ pesagem $)$ & 40,61 & 44,20 & 46,18 & $43,66 \mathrm{~A}$ \\
\hline Média & $40,92 \mathrm{~b}$ & $44,06 a$ & $45,58 \mathrm{a}$ & \\
\hline
\end{tabular}

$\mathrm{CV}(\%)=3,97$

Teste $\mathrm{F}(\mathrm{T})=32,54^{* *}$

Teste $\mathrm{F}(\mathrm{P})=1,39^{\mathrm{NS}}$

Teste $\mathrm{F}(\mathrm{P} \mathrm{X} \mathrm{T})=0,42^{\mathrm{NS}}$

a, b Médias, seguidas de letras diferentes, diferem entre si pelo teste de Tukey a 5\% de probabilidade. Nas linhas, letras minúsculas

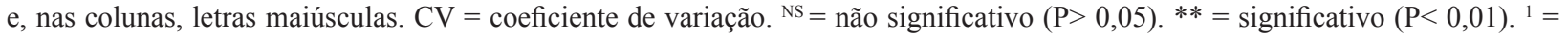
Escala de condição corporal de 1 a $5 \cdot^{2}=\mathrm{kg}$. $\mathrm{P}=$ período experimental (avaliação a cada 21 dias).

Fonte: Elaboração dos autores.

O peso corporal das ovelhas não foi influenciado $(\mathrm{P}<0,05)$ pelos períodos experimentais de 21 dias, com valor médio de 43,51 kg. O escore de condição corporal das ovelhas (OL, OSC e ONP) não foi 
influenciada $(\mathrm{P}>0,05)$ durante os períodos 1 e 2 , com valor médio de 2,16. Isso pode ter ocorrido, principalmente, porque as ovelhas do tratamento 2 estavam ainda em lactação, e também pelas ovelhas do tratamento 1 já estarem no primeiro mês da lactação e, consequentemente, seus cordeiros já estavam consumindo concentrado. No período experimental 3 houve um aumento $(\mathrm{P}<001)$ no escore de condição corporal das ovelhas em relação aos demais períodos (Tabela 1). Segundo Komaragiri, Casper e Erdman (1998) e Rennó et al.
(2006) o período de lactação é o momento de maior desgaste fisiológico da vida do animal, promovendo perda de peso, e principalmente, de tecido adiposo e muscular, estando condizentes com o verificado nas Tabelas 1,2 e 3 deste estudo.

Não houve interação $(\mathrm{P}>0,05)$ entre os períodos e tratamentos experimentais para EGS e CMM Longissimus dorsi entre a $12^{\text {a }}$ e $13^{\text {a }}$ costelas de ovelhas de descarte (Tabela 2); no entanto, para a PMM ocorreu $(\mathrm{P}<0,05)$ interação entre os períodos e tratamentos avaliados.

Tabela 2. Determinação da espessura de gordura subcutânea (EGS), do comprimento e da profundidade máxima do músculo (CMM e PMM) Longissimus dorsi entre a $12^{\mathrm{a}}$ e $13^{\mathrm{a}}$ costelas por ultrassom em ovelhas em distintos estágios fisiológicos e períodos experimentais de 21 dias cada.

\begin{tabular}{|c|c|c|c|c|}
\hline \multirow{2}{*}{ Variável } & \multicolumn{3}{|c|}{ Tratamento $(\mathrm{T})$} & \multirow{2}{*}{ Média } \\
\hline & $\mathrm{OL}$ & OSC & ONP & \\
\hline \multicolumn{5}{|l|}{$\mathrm{EGS}^{1}$} \\
\hline P1 ( $1^{\circ}$ avaliação com ultrassom $)$ & 1,30 & 1,54 & 1,90 & $1,58 \mathrm{~B}$ \\
\hline P2 ( $2^{\circ}$ avaliação com ultrassom $)$ & 1,43 & 1,44 & 2,12 & $1,66 \mathrm{~B}$ \\
\hline P3 ( $3^{\circ}$ avaliação com ultrassom $)$ & 1,43 & 2,20 & 2,65 & $2,09 \mathrm{~A}$ \\
\hline Média & $1,38 \mathrm{~b}$ & $1,73 \mathrm{ab}$ & $2,22 \mathrm{a}$ & \\
\hline
\end{tabular}

$\mathrm{CV}(\%)=21,59$

Teste $\mathrm{F}(\mathrm{T})=27,07^{* *}$

Teste $\mathrm{F}(\mathrm{P})=10,24 * *$

Teste F $(\mathrm{P} \mathrm{X} \mathrm{T})=2,36^{\mathrm{NS}}$

\begin{tabular}{|c|c|c|c|c|}
\hline $\mathrm{CMM}^{2}$ & & & & \\
\hline P1 ( $1^{\circ}$ avaliação com ultrassom ) & 4,82 & 5,37 & 5,40 & $5,19 \mathrm{~B}$ \\
\hline P2 $\left(2^{\circ}\right.$ avaliação com ultrassom $)$ & 5,03 & 5,38 & 5,72 & $5,38 \mathrm{AB}$ \\
\hline P3 ( $3^{\circ}$ avaliação com ultrassom ) & 5,08 & 5,76 & 5,68 & $5,51 \mathrm{~A}$ \\
\hline Média & $4,98 \mathrm{~b}$ & $5,50 \mathrm{a}$ & $5,60 \mathrm{a}$ & \\
\hline
\end{tabular}

$\mathrm{CV}(\%)=6,04$

Teste $\mathrm{F}(\mathrm{T})=22,51^{* *}$

Teste $\mathrm{F}(\mathrm{P})=4,88^{* *}$

Teste $\mathrm{F}(\mathrm{P} \mathrm{X} \mathrm{T})=0,84^{\mathrm{NS}}$

\begin{tabular}{lllll}
\hline PMM $^{3}$ & & & & \\
\hline P1 $\left(1^{\circ}\right.$ avaliação com ultrassom $)$ & $2,10 \mathrm{ABa}$ & $2,26 \mathrm{Bab}$ & $2,42 \mathrm{a}$ & $2,26 \mathrm{~B}$ \\
P2 $\left(2^{\circ}\right.$ avaliação com ultrassom $)$ & $2,03 \mathrm{Bb}$ & $2,21 \mathrm{Bb}$ & $2,55 \mathrm{a}$ & $2,26 \mathrm{~B}$ \\
P3 $\left(3^{\circ}\right.$ avaliação com ultrassom $)$ & $2,32 \mathrm{~A}$ & $2,52 \mathrm{~A}$ & 2,52 & $2,45 \mathrm{~A}$ \\
Média & $2,15 \mathrm{~b}$ & $2,33 \mathrm{ab}$ & $2,50 \mathrm{a}$ & \\
\hline
\end{tabular}

$\mathrm{CV}(\%)=6,38$

Teste $\mathrm{F}(\mathrm{T})=29,12 * *$

Teste $\mathrm{F}(\mathrm{P})=11,59^{* *}$

Teste F $(\mathrm{P} \mathrm{X} \mathrm{T})=2,96 *$

a, b Médias, seguidas de letras diferentes, diferem entre si pelo teste de Tukey a 5\% de probabilidade. Nas linhas, letras minúsculas, e, nas colunas, letras maiúsculas. $\mathrm{CV}=$ coeficiente de variação. ${ }^{\mathrm{NS}}=$ não significativo $(\mathrm{P}>0,05)$. ${ }^{*}=$ significativo $(\mathrm{P}<0,05)$. $* *=$ significativo $(\mathrm{P}<0,01) .{ }^{1} \mathrm{EGS}=\mathrm{mm} .{ }^{2} \mathrm{CMM}=\mathrm{cm} .{ }^{3} \mathrm{PMM}=\mathrm{cm} . \mathrm{P}=$ período experimental (avaliação com ultrassom a cada 21 dias).

Fonte: Elaboração dos autores. 
A EGS do músculo Longissimus dorsi foi semelhante $(\mathrm{P}>0,05)$ nos períodos 1 e 2 , com valor médio de 1,62 mm. A EGS no período 3 foi maior $(\mathrm{P}<0,01)$ que nos demais períodos experimentais (Tabela 2), proporcionando um aumento significativo da EGS em relação aos demais períodos. A EGS diferiu $(\mathrm{P}<0,01)$ entre os tratamentos estudados (Tabela 2), com menor valor médio de EGS sobre o músculo Longissimus dorsi para as ovelhas do tratamento $\mathrm{OL}$ em relação às do tratamento $\mathrm{ONP}$. $\mathrm{O}$ tratamento OSC apresentou EGS semelhante (P $>0,05)$ aos demais tratamentos experimentais. A gordura de cobertura determinada por ultrassom entre a $12^{\mathrm{a}}$ e $13^{\mathrm{a}}$ costelas, quando associada com o peso corporal do animal pode ser utilizada para estimar a proporção de gordura corporal total em ovinos (TEIXEIRA et al., 2006; SAHINA et al., 2008).

A medida de CMM Longissimus dorsi foi influenciada $(\mathrm{P}<0,01)$ pelos períodos experimentais 1 e 3, e quanto ao período 2 foi similar os valores médios aos demais tratamentos (Tabela 2). Os valore médios do CMM foi menor para as ovelhas do tratamento $\mathrm{OL}$ em relação às dos tratamentos ONP nos períodos experimentais. Segundo Pinheiro, Jorge e Yokoo (2010) o comprimento máximo do músculo Longissimus dorsi de ovinos determinados in vivo por ultrassom, como na carcaça, apresentam alta correlação com a área de olho-de-lombo.

$\mathrm{O}$ valor médio de $\mathrm{PMM}$ foi igual $(\mathrm{P}>0,05)$ para os períodos 1 e 2 , sendo inferior $(\mathrm{P}<0,01)$ à do período 3; portanto, houve um aumento de $8,40 \%$ da PMM Longissimus dorsi. A média geral do PMM diferiu $(\mathrm{P}<0,01)$ entre os tratamentos, apresentando valores inferiores para a PMM das ovelhas do tratamento $\mathrm{OL}$ em relação às do tratamento ONP (Tabela 2).

$\mathrm{O}$ período experimental influenciou $(\mathrm{P}<0,01)$ os valores médios de AOL e AOLA do músculo Longissimus dorsi de ovelhas de descarte (Tabela
3), com menor área do músculo Longissimus dorsi no período 1 e com maior área no período 3. Do período 1 ao 2 houve um aumento de 9,64\% de AOL e de $11,32 \%$ de AOLA e do período 2 ao 3 houve um aumento de $11,58 \%$ de AOL e 12,43\% AOLA, e do período 1 ao 3 um aumento de 11,59\% de AOL e 12,43\% AOLA. Não houve interação entre os períodos e tratamentos experimentais para AOL e AOLA (Tabela 3). De acordo com Nash et al. (2000) e Silva et al. (2003) a AOL apresenta crescimento linear em relação ao peso corporal do animal.

As AOL e AOLA diferiram significativamente $(\mathrm{P}<0,01)$ entre os tratamentos, com menor valor médio para o tratamento OL em relação ao tratamento ONP (Tabela 3). De acordo com Bergen et al. (1997) a relação entre a medida de AOL e o peso corporal do animal é utilizada para reduzir a influência do peso corporal e do grau de musculosidade dos diferentes animais e grupos genéticos, facilitando a comparação dos mesmos com maior acurácia. Segundo Suguisawa et al. (2002) a AOL tem relação com a musculosidade da carcaça. Portanto, quanto maior a área de olho de lombo, maior será a proporção de músculos na carcaça, o que é muito desejado atualmente na produção animal.

As variáveis avaliadas in vivo nesta pesquisa apresentaram correlação baixa entre si (Tabela 4), com exceção da AOL com o ECC, PMM, CMM e AOLA que apresentaram alta correlação entre si. Portanto, a melhora da condição corporal das ovelhas indica maior AOL do músculo Longissimus dorsi entre a $12^{\mathrm{a}}$ e $13^{\mathrm{a}}$ costelas, assim como, o aumento das medidas de PMM, CMM e AOLA indicam, também, maior AOL do respectivo músculo. A condição corporal apresenta valores médios de correlação com a EGS (Tabela 4). Cartaxo e Sousa (2008) também obtiveram correlação alta entre a AOL e a condição corporal. Manzano et al. (1999) obtiveram correlação de 0,47 entre o peso corporal e a condição corporal de ovelhas da raça Pelibuey, valor este superior ao deste estudo (Tabela 4). 
Tabela 3. Valor da área de olho de lombo (ALO) e da área de olho de lombo ajustada (AOLA) do músculo Longissimus dorsi entre a $12^{\mathrm{a}}$ e $13^{\mathrm{a}}$ costelas determinado por ultrassom em ovelhas em distintos estágios fisiológicos e períodos experimentais de 21 dias cada.

\begin{tabular}{lcccc}
\hline \multirow{2}{*}{ Variável } & \multicolumn{3}{c}{ Tratamento $(\mathrm{T})$} & \multirow{2}{*}{ Média } \\
\cline { 2 - 4 } & OL & OSC & ONP & \\
\hline $\mathrm{ALO}^{1}$ & & & & \\
$\mathrm{P} 1\left(1^{\circ}\right.$ avaliação com ultrassom $)$ & 7,56 & 9,39 & 10,44 & $10,01 \mathrm{~B}$ \\
P2 $\left(2^{\circ}\right.$ avaliação com ultrassom $)$ & 8,25 & 9,71 & 12,07 & $11,17 \mathrm{~A}$ \\
P3 (3 ${ }^{\circ}$ avaliação com ultrassom $)$ & 9,50 & 11,75 & 12,26 & \\
Média & $8,44 \mathrm{~b}$ & $10,28 \mathrm{ab}$ & $11,59 \mathrm{a}$ & \\
\hline
\end{tabular}

$\mathrm{CV}(\%)=8,31$

Teste $\mathrm{F}(\mathrm{T})=74,65^{* *}$

Teste $\mathrm{F}(\mathrm{P})=31,10^{* *}$

Teste $\mathrm{F}(\mathrm{P} X \mathrm{~T})=2,29^{\mathrm{NS}}$

\begin{tabular}{lllll}
\hline AOLA $^{2}$ & & & & \\
\hline P1 $\left(1^{\circ}\right.$ avaliação com ultrassom $)$ & 2,93 & 3,06 & 3,55 & $3,18 \mathrm{C}$ \\
P2 $\left(2^{\circ}\right.$ avaliação com ultrassom $)$ & 3,28 & 3,20 & 4,14 & $3,54 \mathrm{~B}$ \\
P3 $\left(3^{\circ}\right.$ avaliação com ultrassom $)$ & 3,82 & 3,96 & 4,16 & $3,98 \mathrm{~A}$ \\
Média & $3,34 \mathrm{~b}$ & $3,41 \mathrm{~b}$ & $3,95 \mathrm{a}$ & \\
\hline
\end{tabular}

$\mathrm{CV}(\%)=9,00$

Teste $\mathrm{F}(\mathrm{T})=22,67^{* *}$

Teste $\mathrm{F}(\mathrm{P})=32,46^{* *}$

Teste $\mathrm{F}(\mathrm{P} \mathrm{X} \mathrm{T})=2,55^{\mathrm{NS}}$

a, b Médias, seguidas de letras diferentes, diferem entre si pelo teste de Tukey a 5\% de probabilidade. Nas linhas, letras minúsculas, e, nas colunas, letras maiúsculas. $\mathrm{CV}=$ coeficiente de variação. ${ }^{\mathrm{NS}}=$ não significativo $(\mathrm{P}>0,05)$. ${ }^{*}=$ significativo $(\mathrm{P}<0,05)$. ${ }^{* *}=$ significativo $(\mathrm{P}<0,01) \cdot{ }^{1} \mathrm{AOL}=\mathrm{cm}^{2} .{ }^{2} \mathrm{AOLA}=\mathrm{cm}^{2} / 15 \mathrm{~kg}$ de carcaça. $\mathrm{P}=$ período experimental (avaliação com ultrassom a cada 21 dias).

Fonte: Elaboração dos autores.

Tabela 4. Coeficiente de correlação de Pearson entre as medidas realizadas por ultrassom in vivo, escore de condição corporal e peso corporal de ovelhas de descarte em diferentes estágios fisiológicos.

\begin{tabular}{lccccccc}
\hline \multicolumn{1}{c}{ Variável } & & ECC & PC & EGS & PMM & CMM & AOL \\
\hline PC & P & 0,01 & & & & & \\
EGS & $\mathrm{r}$ & 0,39 & & & & & \\
\multirow{2}{*}{ PMM } & $\mathrm{P}$ & 0,01 & 0,01 & & & & \\
& $\mathrm{r}$ & 0,67 & 0,47 & & & & \\
CMM & $\mathrm{P}$ & 0,01 & 0,01 & 0,01 & & & \\
& $\mathrm{r}$ & 0,58 & 0,50 & 0,55 & & & \\
AOL & $\mathrm{P}$ & 0,01 & 0,01 & 0,01 & 0,01 & & \\
& $\mathrm{r}$ & 0,56 & 0,54 & 0,48 & 0,53 & & \\
AOLA & $\mathrm{P}$ & 0,01 & 0,01 & 0,01 & 0,01 & 0,01 & \\
& $\mathrm{r}$ & 0,71 & 0,61 & 0,62 & 0,84 & 0,81 & \\
& $\mathrm{P}$ & 0,01 & 0,73 & 0,01 & 0,01 & 0,01 & 0,01 \\
& $\mathrm{r}$ & 0,58 & 0,04 & 0,42 & 0,65 & 0,58 & 0,75 \\
\hline
\end{tabular}

$\mathrm{PC}=$ Peso corporal. $\mathrm{ECC}=$ escore de condição corporal. EGS = Espessura de gordura subcutânea. PMM = Profundidade máxima do músculo. $\mathrm{CMM}=$ Comprimento máxima do músculo. $\mathrm{AOL}=$ Área de olho de lombo. AOLA = Área de olho de lombo ajustada $\left(\mathrm{cm}^{2} / 15 \mathrm{~kg}\right.$ de carcaça).

Fonte: Elaboração dos autores. 


\section{Conclusões}

A utilização do ultrassom em tempo real permite monitorar as mudanças que ocorrem com a gordura subcutânea e o músculo Longissimus dorsi entre a $12^{\mathrm{a}}$ e $13^{\mathrm{a}}$ costelas de ovelhas. Mudanças estas que ocorrem com uma frequência maior em intervalos de 42 dias dos tecidos muscular e adiposo.

Ovelhas que permanecem em lactação por 60 dias apresentam pior condição corporal, menor peso corporal, além de menor comprimento máximo do músculo Longissimus dorsi entre $12^{\mathrm{a}}$ e $13^{\mathrm{a}}$ costelas que as ovelhas em outros estágios fisiológicos estudados.

\section{Referências}

BERGEN, R. D.; McKINNON, J. J.; CHRISTENSEN, D. A.; KOHLE, N.; BELANGER, A. Use of the realtime ultrasound to evaluate live animal carcass traits in young performance-tested beef bulls. Journal of Animal Science, Savoy, v. 73, n. 9, p. 2300-2307, 1997.

CARTAXO, F. Q.; SOUSA, W. H. Correlações entre as características obtidas in vivo por ultra-som e as obtidas na carcaça de cordeiros terminados em confinamento. Revista Brasileira de Zootecnia, Viçosa, v. 37, n. 8, p. 1490-1495, 2008.

CASTRO, F. A. B.; RIBEIRO, E. L. A.; KORITIAKI, N. A.; MIZUBUTI, I. Y.; SILVA, L. D. F.; PEREIRA, E. S.; PINTO, A. P.; CONSTANTINO, C.; FERNANDES JUNIOR, F. Desempenho de cordeiros Santa Inês do nascimento ao desmame filhos de ovelhas alimentadas com diferentes níveis de energia. Semina: Ciências Agrárias, Londrina, v. 33, n. 6, p. 3379-3388, 2012.

FROST, A. R.; SCHOFIELD, C. P.; BEAULAH, S. A.; MOTTRAM, T. T.; LINES, J. A.; WATHES, C. M. A review of livestock and monitoring and the need for integrated systems. Computers and Electronics in Agriculture, Amsterdam, v. 17, n. 2, p. 139-159, 1997.

GERON, L. J. V.; MEXIA, A. A.; GARCIA, J.; SILVA, M. M.; ZEOULA, L. M. Suplementação concentrada para cordeiros terminados a pasto sobre custo de produção no período da seca. Semina: Ciências Agrárias, Londrina, v. 33, n. 2, p. 797-808, 2012.

GODFREY, R. W.; GRAY, M. L.; COLLINS, J. R. Lamb growth and milk production of hair and wool sheep in a semi-arid tropical environment. Small Ruminant Research, Amsterdam, v. 24, n. 2, p. 77-83, 1997.
KOMARAGIRI, M. V. S.; CASPER, D. P.; ERDMAN, R. A. Factors affecting body tissue mobilization in early lactation dairy cows. 2. Effect of dietary fat on mobilization of body fat and protein. Journal of Dairy Science, Madison, v. 81, n. 1, p. 169-175, 1998.

MANZANO, C. E.; MINIET, R. G.; MOYA, G. M.; ÁLVAREZ, E. L.; JIMÉNEZ, Y. F. Relación entre peso vivo, condición corporal e indicadores bioquímicos de la nutrición en ovejas vacías y secas de la raza Pelibuey. Archivos de Zootecnia, Córdoba, v. 48, n. 182, p. 223226. 1999.

NASH, S. A.; HARRISON, S. N.; PACKHAM, J. H.; PANTING, R. R.; PAS, S. K. D. Case study: Monitoring changes in carcass quality across time-on-feed using real-time ultrasound to optimize marketing endpoints. The Professional Animal Scientist, Champaign, v. 16, n. 3, p. 202-205, 2000.

PEDRON, O.; CHELI, F.; SENATORE, E.; BAROLI, D.; RIZII, R. Effect of body condition score at calving on performance, some blood parameters, and milk fat acid composition in dairy cows. Journal of Dairy Science, Madison, v. 76, n. 9, p. 2528-2535, 1993.

PINHEIRO, R. S. B.; JORGE, A. M.; YOKOO, M. J. Correlações entre medidas determinadas in vivo por ultrassom e na carcaça de ovelhas de descarte. Revista Brasileira de Zootecnia, Viçosa, v. 39, n. 5, p. 11611167, 2010.

RENNÓ, F. P.; PEREIRA, J. C.; SANTOS, A. D. F.; ALVES, N. G.; TORRES, C. A. A.; RENNÓ, L. N.; BALBINOT, P. Z. Efeito da condição corporal ao parto sobre a produção e composição do leite, a curva de lactação e a mobilização de reservas corporais em vacas da raça Holandesa. Arquivo Brasileiro de Medicina Veterinária e Zootecnia, Belo Horizonte, v. 58, n. 2, p. 220-233, 2006.

RUSSEL, A. J. F.; DONEY, J. M.; GUNN, R. G. Subjective assessment of body fat in live sheep. Journal Agricultural Science, Cambridge, v. 72, n. 3, p. 451-454, 1969.

SAHINA, E. H.; YARDIMCIA, M.; CETINGULB, I. S.; BAYRAMB, I.; SENGOR, E. The use of ultrasound to predict the carcass composition of live Akkaraman lambs. Meat Science, Champaign, v. 79, n. 4, p. 716-721, 2008.

SILVA, S. L.; LEME, P. R.; PEREIRA, A. S. C.; PUTRINO, S. M. Correlações entre características de carcaça avaliadas por ultra-som e pós-abate em novilhos Nelore, alimentados com altas proporções de concentrado. Revista Brasileira de Zootecnia, Viçosa, v. 32, n. 5, p. 1236-1242, 2003. 
STANFORD, K.; McALLISTER, T. A.; MacDOUGALL, M.; BAILEY, D. R. C. Use of ultrasound for the prediction of carcass characteristics in Alpine goats. Small Ruminant Research, Amsterdam, v. 15, n. 2, p. 195-201, 1995.

SAS - STATISTICAL ANALYSIS SYSTEM. Institute Inc., Statistical analysis system user's guide. Version 9. 13. ed. Cary, NC: SAS Institute Inc., 2002.

SUGUISAWA, L.; SOUTELLO, R. V. G.; MATTOS, W. R. S.; BURINI, D. C. M.; STORTI, S. M. M.; BAIER, M. O.; OLIVEIRA, J. J. F. Mensurações ultra-sonográficas relacionadas às características da carcaça de bovinos superprecoces. Ciências Agrárias, Andradina, v. 2, n. 2, p. 13-19, 2002.
TEIXEIRA, A.; MATOSA, S.; RODRIGUESA, S.; DELFAB, R.; CADAVEZ, V. In vivo estimation of lamb carcass composition by real-time ultrasonography. Meat Science, Champaign, v. 74, n. 2, p. 289-295, 2006.

THWAITES, C. J. Ultrasonic estimation of carcass composition - review. [S.1.: s.n], 1984. 29 p. (Australian Meet Research Committee, n. 47).

WALTNER, S. S.; McNAMARA, J. P.; HILLERS, J. K. Relationships of body condition score to production variables in high producing Holstein dairy cattle. Journal of Dairy Science, Madison, v. 76, n. 11, p. 3410-3419, 1993. 
